\title{
MERJENJE MALIH ALPSKIH LEDENIKOV: PRIMERI IZ SLOVENIJE IN AVSTRIJE
}

MEASUREMENTS OF SMALL ALPINE GLACIERS: EXAMPLES FROM SLOVENIA AND AUSTRIA

\author{
Mihaela Triglav Čekada, Matija Zorn, Viktor Kaufmann, Gerhard Karl Lieb
}

\section{UDK: $528.4+528.7(234.2)(497.4)(436)$ \\ IZVLEČEK}

V zadnjem stoletju in pol se globalne povprečne letne temperature stalno dvigajo. Ena od vidnih posledic tega je spreminjanje velikosti ledenikov. Za spremljanje površinskih in prostorninskih sprememb ledenikov obstajajo številne metode, od meritev z merskim trakom, klasičnih geodetskih izmer do daljinskega zaznavanja in fotogrametrije. Uporaba nekaterih je predstavljena na dveh slovenskih (Triglavski ledenik, Ledenik pod Skuto) in dveh avstrijskih ledenikih (Gössnitzkees in Hornkees). Predstavljen je tudi dolgoročen trend zmanjševanja ledenikov Gössnitzkees, Hornkees in Triglavskega ledenika, ki ga na podlagi različnih arhivskih podatkov lahko spremljamo že od začetka 20. stoletja. Čeprav so obravnavani ledeniki različno veliki, izkazujejo primerljiv letni trend zmanjševanja v obdobju med letoma 1929 in 2006.

\section{KLJUČNE BESEDE}

mali alpski ledeniki, geodetska izmera, fotogrametrična izmera, Avstrija, Slovenija
Klasifikacija prispevka po COBISS-u: 1.02

\begin{abstract}
In the last century and a half, average summer temperatures have slowly been rising worldwide. The most observable consequence of this is the change in glacier sizes. For monitoring glacier area and volume, various measuring techniques exist-from measurements with a measuring tape and geodetic measurements to remote sensing and photogrammetry. A comparison of different measuring techniques on two Slovenian glaciers (the Triglav and Skuta glaciers) and two Austrian glaciers (the Gössnitzkees and Hornkees glaciers) is made. A long-term glacial retreat trend is presented for the Gössnitzkees, Hornkees, and Triglav glaciers because these glaciers can be monitored throughout the entire twentieth century by means of archival data. Despite their different sizes, the annual trend of glacial retreat was approximately the same in the period between 1929 and 2006.
\end{abstract}

\section{KEY WORDS}

small alpine glaciers, geodetic measurements, photogrammetric measurements, Austria, Slovenia

\section{UVOD}

Alpski ledeniki so pomembna hidrološka in geomorfološka naravna dediščina, so pa tudi vir pitne vode in pomembna turistična destinacija (Zängl in Hamberger, 2004). Z njihovim opazovanjem je mogoče spremljati kratkoročne podnebne spremembe v Alpah, s preučevanjem njihovih akumulacijskih oblik pa tudi starejše okoljske spremembe (Kuhn, 1979; Haeberli et al., 2007).

Z meritvami ledenikov največkrat preučujemo umikanje čela ledenika, zmanjševanje površine ali prostornine in hitrost premikanja ledenika. V Alpah, kjer so ledeniki na višje ležečih območjih, je terensko delo oteženo, zato so se prve meritve izvajale pretežno ročno - uporabili so merski 
trak in kompas. Že leta 1878 so z rednimi meritvami z merskim trakom začeli meriti umikanje čela ledenika Pasterca (Pasterze am Großglockner) v Avstriji, najdaljšega ledenika ${ }^{1}$ v Vzhodnih Alpah (Kienast in Kaufman, 2004; Lieb, 2004). Redne meritve slovenskih malih ledenikov (Triglavski ledenik in Ledenik pod Skuto) so z merskim trakom začeli izvajati leta 1946 (Natek in Perko, 1999; Gabrovec, 2002; 2008).

Kmalu so ledenike začeli meriti tudi s klasično geodetsko izmero. Na ledeniku Pasterca so na primer leta 1928 uporabili klasično tahimetrično geodetsko metodo za izmero petih prečnih prerezov ledenika. Na severovzhodnem delu ledenika so postavili stojišča izmere, na nasprotni strani pa so na skalah z barvo označili končne točke prečnega prereza. Med stojišče in končno točko prereza so po ledeniku položili velike kamne, ki so bili v pomoč pri izmeri. Večino kamnov so lahko uporabili tudi v naslednjih letih pri ponovnih izmerah. Vsak prerez je bil izmerjen v svojem lokalnem koordinatnem sistemu, zato ti podatki niso bili neposredno uporabni za preučevanje zmanjševanja prostornine ledenika. Podatke so pretvorili v skupen koordinatni sistem šele leta 1996, ko so izvedli prvo izmero stojišč in končnih točk prerezov z globalnim navigacijskim satelitskim sistemom (GNSS-izmera) (Kienast in Kaufman, 2004).

Zadnjih nekaj desetletij alpske ledenike merijo večinoma z različnimi metodami daljinskega zaznavanja: od terestrične in aerofotogrametrije do obdelave satelitskih posnetkov ter uporabe terestričnih in aerolaserskih podatkov (Kienast in Kaufman, 2004; Avian in Bauer, 2006; Bolch in Kamp, 2006; Haeberli et al., 2007; Kaufmann in Ladstädter, 2008a; Kaufmann in Ladstädter, 2008b; Hagg et al., 2008; Knoll in Kerschner, 2009; Abermann et al., 2009). Tako so na primer zmanjševanje ledenika Pasterca med letoma 1984 in 1990 že ugotavljali na podlagi satelitskih posnetkov Landsat (Bayr et al., 1994).

Med približno devetsto avstrijskimi ledeniki smo za primerjavo s slovenskima izbrali dva, na katerih se že več desetletij kontinuirano izvajajo klasične geodetske in fotogrametrične meritve in ju že vrsto let spremljajo soavtorji prispevka. Poudarek je na predstavitvi metod izmere ledenikov, a na kratko predstavljamo tudi krajevne trende zmanjševanja malih ledenikov v jugovzhodnem delu Alp.

\section{SLOVENSKA LEDENIKA}

V Sloveniji imamo dva majhna ledenika: Triglavski ledenik (slike 1, 3, 4, 5, 6) in Ledenik pod Skuto (slike 2, 7, 8). V primerjavi z večjimi alpskimi ledeniki sta oba na relativno nizki nadmorski višini. Triglavski ledenik je na višini med 2400 in 2500 metrov, Ledenik pod Skuto pa med 2020 in 2120 metrov. Ledenik pod Skuto je primer krniškega ledenika z izrazito osojno lego skoraj vse leto. Pretežen del njegove površine je prekrit z gruščem. Nasprotno pa ima Triglavski ledenik prisojno lego. O obsegu, ki sta ga ledenika imela ob zadnjem višku male ledene dobe okrog leta 1850, lahko sklepamo iz morenskih ostankov (Šifrer, 1963; Pavšek, 2007).

Dandanes je izmed ledeniških značilnosti na ledenikih mogoče opaziti le ledeniški led, drugih ledeniških značilnosti, povezanih s premikanjem ledene gmote, pa na njiju ne moremo več videti.

${ }^{I}$ Pasterca je bil leta 1850 dolg 11,4 km, v letu 2002 pa 8,4 km in njegova površina se je v tem času zmanjšala z 2650 ha na 1850 ha (Avian in Bauer, 2006). 
Še med obema vojnama je bil na primer Triglavski ledenik prepreden s številnimi globokimi prečnimi ledeniškimi razpokami, ki so pričale o premikanju ledene gmote (slika 1). V prvih letih sistematičnih merjenj (meritve so se začele leta 1946), do približno leta 1955, so na Triglavskem ledeniku še vedno opazili manjše ledeniške razpoke, ki pa so potekale vzporedno s smerjo gibanja ledenika. Leta 1950 je bila največja globina razpoke 8,6 metra in ni segala do dna ledenika. Meze (1955) je razpoke opisal kot zelo borne, a z današnjega stališča so bile precej globoke. Posamezne plitve vzdolžne ledeniške razpoke v osrednjem delu ledenika so opazovali še leta 1973 predvsem tam, kjer se je pozneje izkazalo, da je bil ledenik najtanjši in se je led premikal čez obsežne skalne grbine.

Triglavski ledenik je poleti med letoma 1954 in 1962 napajal tudi majhna ledeniška jezerca. Leta 1954 je bila večina jezerc širokih in dolgih nekaj metrov (od $4 \mathrm{~m}$ do $10 \mathrm{~m}$ ) z največjo globino do 90 centimetrov. Največje med njimi je bilo veliko približno $100 \mathrm{~m}^{2}$ (Meze, 1955).

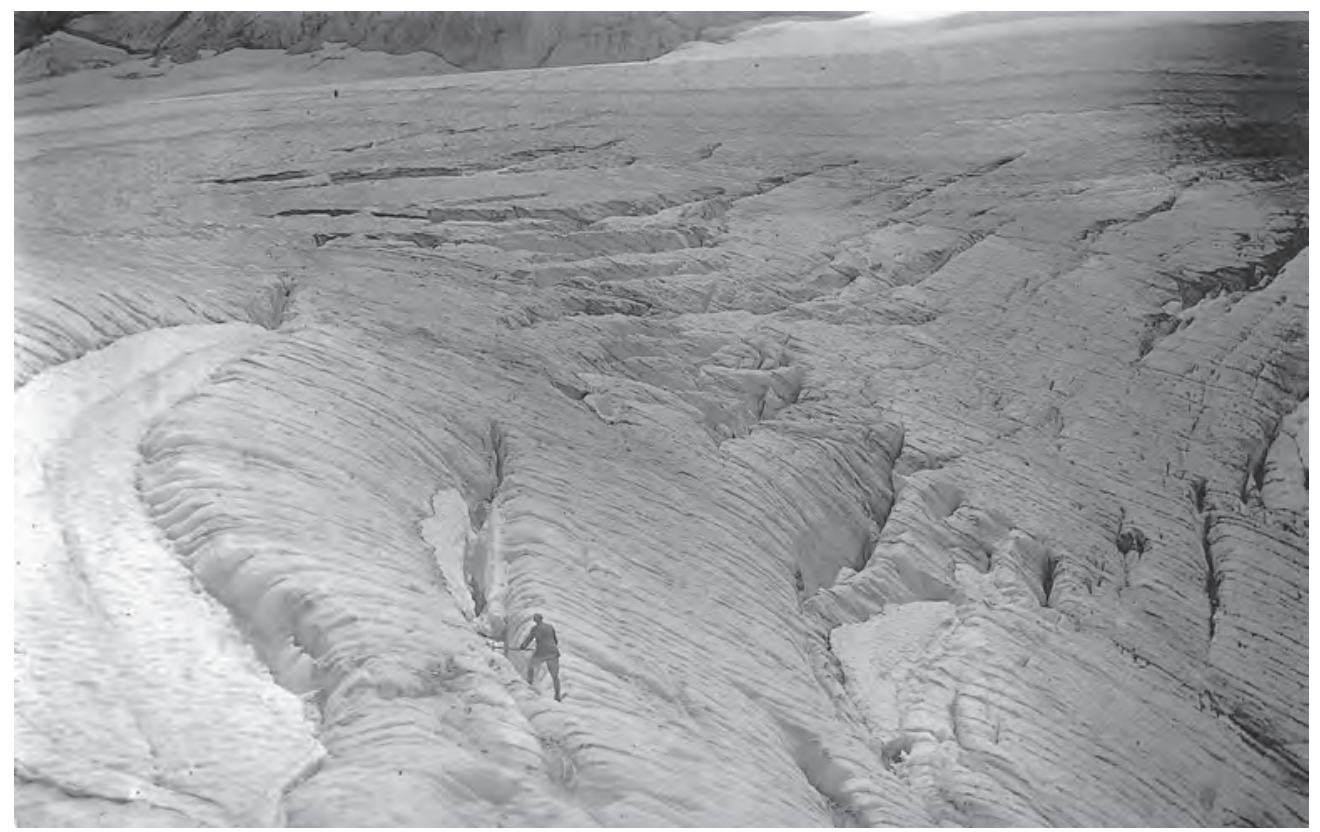

Slika 1: Prečne ledeniške razpoke na Triglavskem ledeniku leta 1924 (Kunaver, 1949) (fotograf: Josip Kunaver)

Ledeniške razpoke je imel tudi Ledenik pod Skuto. Prvič so omenjene v poročilu gorske nesreče iz leta 1913 (slika 2); globoke so bile od 10 do 15 metrov. Na zgornjem najstrmejšem delu Ledenika pod Skuto so posamezne prečne ledeniške razpoke opazili še v letu 1973. Po meritvah leta 1961 je bila največja prečna razpoka dolga približno 60 metrov in je imela največjo globino približno 7 metrov, leta 1966 pa je bila ista razpoka dolga le 28 metrov in globoka 5 metrov (Meze, 1955; Šifrer in Košir, 1976). 


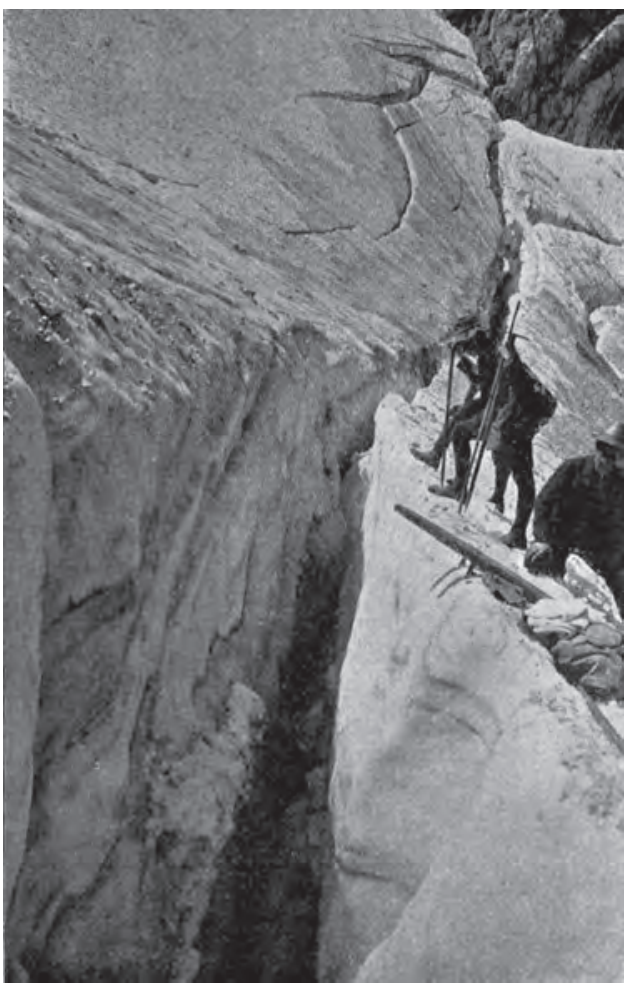

Slika 2: Prečna ledeniška razpoka na Ledeniku pod Skuto leta 1913 (Kunaver, 1913) (fotograf: Josip Kunaver)

\subsection{Izmera Triglavskega ledenika}

Redna letna merjenja Triglavskega ledenika so se začela leta 1946. Izvajajo jih na Geografskem inštitutu Antona Melika ZRC SAZU (preglednica 1). Sprva so vsakoletne meritve ob koncu talilne dobe izvajali ročno z merskim trakom, vrvjo in kompasom. Merili so odmik ledu oziroma snega od črt in pik, označenih po skalah okrog ledenika. Prvotno so merili vertikalni odmik ledenika od teh oznak, s čimer so spremljali njegovo tanjšanje. Ko pa se je ledenik začel hitreje tanjšati in v spodnjem delu razpadati, so na skale okoli ledenika dorisali še črte, ki prikazujejo, do kod je v določenem letu segal (Meze, 1955; Šifrer, 1963). Mnogo oznak je še vedno mogoče prepoznati (slika 3).

Prva leta so poskušali meriti tudi premikanje ledenika, a neuspešno. Na ledenik so leta 1948 postavili dva kamna, katerih lego so z merskim trakom odmerili od stalnih točk v okolici. Naslednje leto so kamna sicer našli, vendar v dvomljivih legah. Poskus so ponovili leta 1951, le da so kamna zamenjali s štirimi v led zabitimi železnimi palicami. Mesec dni kasneje so na snegu našli samo eno. Dodali so še tri železne palice, vendar naslednje leto niso našli nobene (Meze, 1955).

Prva geodetska meritev s teodolitom je bila opravljena leta 1952, naslednja pa šele leta 1995. Z letom 1999 so se začele redne geodetske tahimetrične meritve ledenika in oslonilnih točk v 
okolici za potrebe fotogrametrične izmere na vsaki dve leti (izvajajo jo sodelavci Geodetskega inštituta Slovenije). V letih 2001 in 2005 se je tahimetrični izmeri pridružila še GNSS-izmera. V letih 1999, 2001 in 2003 je bilo izvedeno ročno aerofotografiranje ožjega obsega ledenika iz helikopterja in terestrično fotogrametrično snemanje z merskim fotoaparatom Rolleiflex 6006. Leta 2005 je bilo izvedeno tudi klasično aerofotogrametrično snemanje širšega območja okoli ledenika z merskim fotogrametričnim fotoaparatom velikega formata Leica RC 30. Po letu 2007 se na ledeniku vsakoletno izvaja tahimetrična izmera z dopolnilnim terestričnim fotogrametričnim snemanjem s fotoaparatom Rolleiflex 6006. Rezultati geodetskih in fotogrametričnih meritev so predstavljeni v merilu 1: 1000 (Triglav Čekada in Gabrovec, 2008; Triglav Čekada, 2012).

Leta 1976 so začeli ledenik redno (približno enkrat mesečno) fotografirati s panoramskim nemerskim fotoaparatom Horizont (Triglav et al., 2000) z dveh stalnih stojišč v okolici Triglavskega doma na Kredarici. Stojišči sta stabilizirani z železnima palicama, na koncu katerih je raven podstavek za fotoaparat. Fotoaparat je bil kalibriran na testnem polju Tehniške univerze na Dunaju v letu 1999. Podatki kalibracije so potrebni za prevzorčenje posnetkov v centralno projekcijo. Izbor prevzorčenih posnetkov, ki prikazujejo ledenik ob koncu talilne dobe, je bil obdelan $\mathrm{z}$ interaktivno metodo orientacije natančnega digitalnega modela reliefa na posamezen posnetek. Uporabljen digitalni model reliefa $\mathrm{z}$ velikostjo celice $2 \mathrm{~m}$ x $2 \mathrm{~m}$ je bil izdelan $\mathrm{s}$ fotogrametričnim zajemom na podlagi posebnega aerofotogrametričnega snemanja
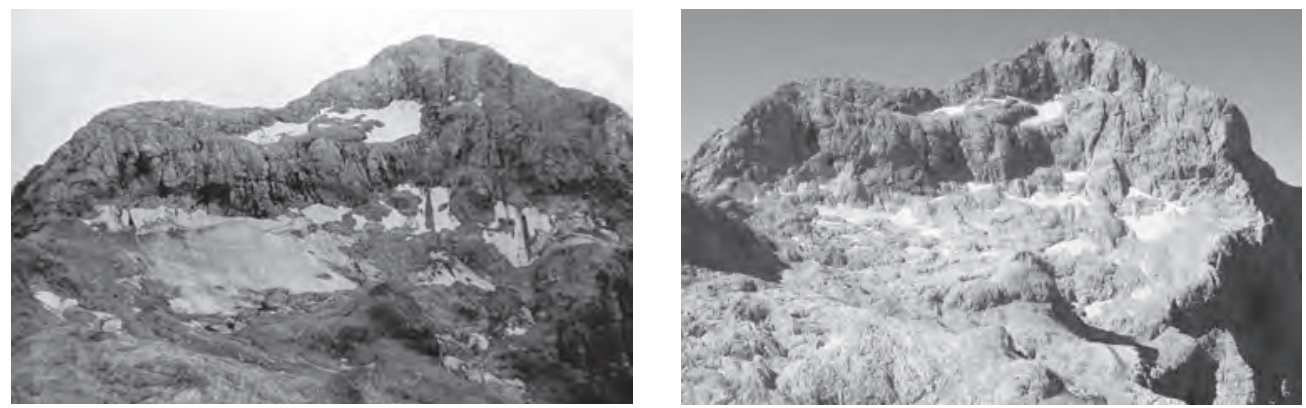

Slika 4: Levo Triglavski ledenik z Begunskega vrha leta 1986 (fotograf: Dušan Košir) in desno ledenik leta 2006 (fotograf: Miha Pavšek)
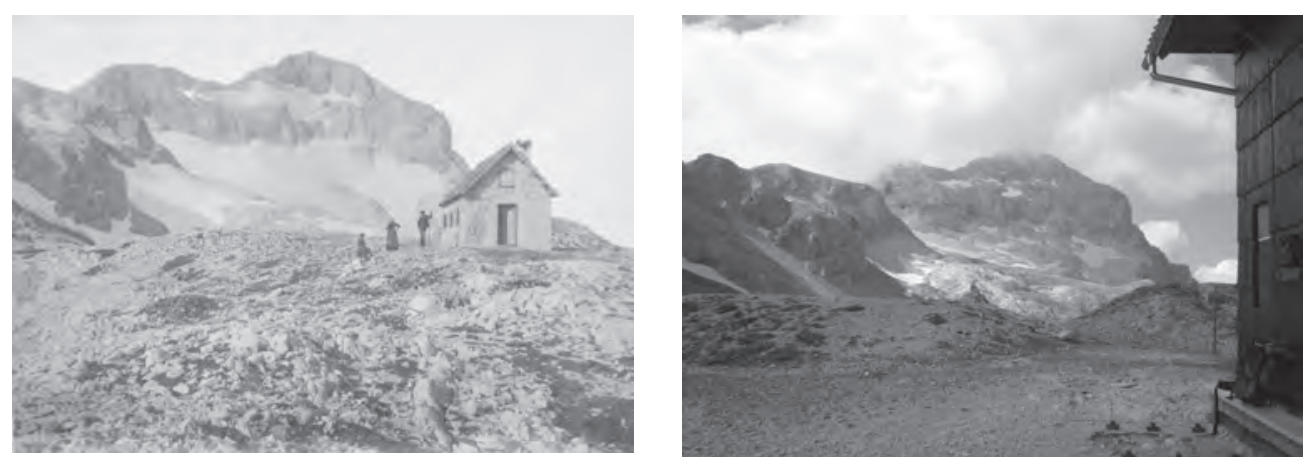

Slika 5: Levo Dežmanova koča (Deschmann-Haus) s Triglavskim ledenikom v ozadju, posneta v obdobju 1887-1889 (fotograf: B. Lergetporer). Desno fotografija Doma Valentina Staniča s Triglavskim ledenikom v ozadju leta 2009 (fotograf: Primož Gašperič). 
ledenika leta 2005. Rezultat zajema so 3D-obodi ledenika, ki so podlaga za izračun njegove površine in prostornine (Triglav Čekada et al., 2011; Triglav Čekada in Gabrovec, 2012).

Podatki o ledeniku so pridobljeni tudi iz stereoparov Cikličnega aerosnemanja Slovenije (CAS), narejenih $\mathrm{z}$ merskim aerofotoaparatom velikega formata; snemanja izvaja Geodetska uprava Republike Slovenije od začetka 70ih let prejšnjega stoletja. Merilo snemanja je večinoma 1: 17.500. Ker ledenik ni vedno posnet ob koncu talilne dobe, so posnetki za njegovo preučevanje le deloma uporabni (na primer le stereopari za leta 1975, 1992, 1994 in 1998). Obseg in površina ledenika sta fotogrametrično vrednotena le iz stereoparov za leti 1975 in 1992. Oba stereopara sta bila absolutno orientirana v državnem koordinatnem sistemu Gauss-Krügerjeve projekcije na podlagi oslonilnih točk, izmerjenih iz steropara CAS 2003. Na steroparu iz leta 1975 leži ledenik v močni senci Triglava, zaradi česar je bil stereozajem močno otežen (Triglav in Gabrovec, 2008).

Vektorizirane so bile tudi plastnice ledenika z državne topografske karte merila $1: 25.000 \mathrm{iz}$ leta 1937.

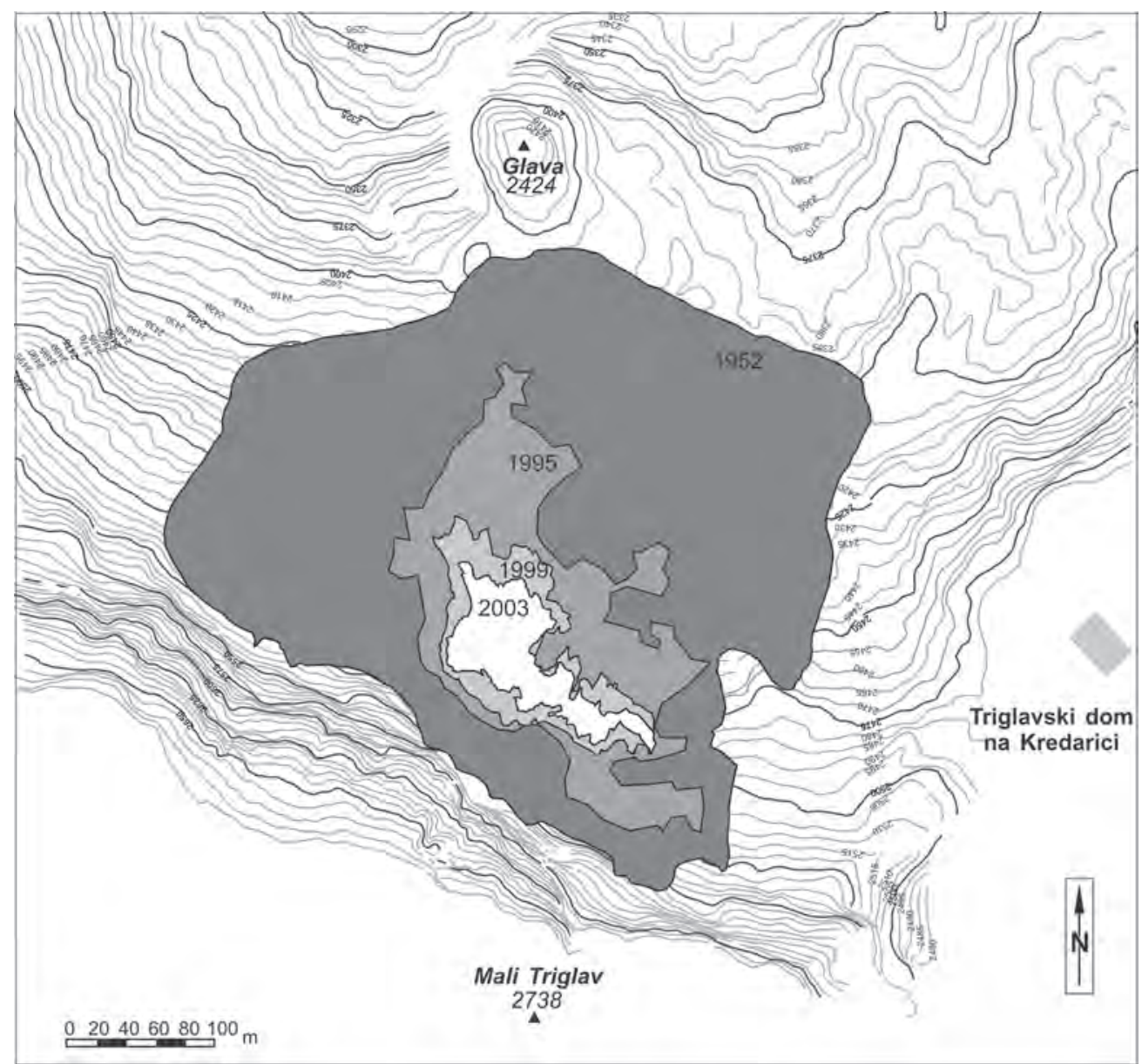

Slika 6: Zmanjševanje površine Triglavskega ledenika med letoma 1952 in 2003 (preglednica 1) 
Debelino ledenika so v letih 1999 in 2000 izmerili z georadarskimi meritvami. Največja debelina ledu je bila v osrednjem delu ledenika 9,5 metra, na bokih ledenika pa ni presegala treh metrov. $\mathrm{Na}$ podlagi teh meritev je bila ocenjena prostornina ledenika na približno $35.000 \mathrm{~m}^{3}$ (Verbič in Gabrovec, 2002).

$\mathrm{Na}$ obdelavo čaka še mnogo arhivskih nemerskih fotografij, narejenih z različnimi fotoaparati, z različnih stojišč in ob različnih letnih časih. Redna fotografiranja ledenika s skoraj stalnih stojišč je predvidel že Meze (1955), saj je leta 1954 v bližini ledenika označil dve mesti, s katerih naj bi vsako leto fotografirali čelo ledenika. Šifrer (1963) poroča še o več stalnih točkah za fotografiranje ${ }^{2}$, od katerih eno - Begunjski vrh - še vedno uporabljajo pri vsakoletnem klasičnem fotografiranju Triglavskega ledenika z različnimi fotoaparati (slika 4).

Ena prvih fotografij Triglavskega ledenika, ki tudi še čaka na obdelavo, je slika Dežmanove koče, posneta med letoma 1887 in 1889 (slika 5). Danes na tem kraju stoji Dom Valentina Staniča $(2332 \mathrm{~m})$.

Zmanjševanje Triglavskega ledenika med letoma 1952 in 2003 je prikazano na sliki 6.

\subsection{Izmera Ledenika pod Skuto}

Tudi meritve na Ledeniku pod Skuto so se začele leta 1946. Uporabljene so bile enake metode za označbo merilnih točk ter meritve z merskim trakom in kompasom kot na Triglavskem ledeniku. Merilne točke so označevale višino, do katere je ledenik segal v posameznem letu. Merili so, koliko se je vertikalno umaknil od merilnih točk. V prvih letih meritev se je predvsem tanjšal in manj površinsko zmanjševal. Tako so neredko izmerili letno višinsko nazadovanje ledenika nekaj višinskih metrov, v zadnjih desetletjih pa od 1 do 1,5 metra na leto (Meze, 1955; Šifrer in Košir, 1976; Pavšek, 2007).

Tudi premikanje Ledenika pod Skuto so se leta 1946, 1948, 1949 in 1951 trudili izmeriti z dva metra dolgimi železnimi palicami, ki so jih vsako leto zapičili v led. Od vseh poskusov jim je leta 1953 uspelo najti le eno železno palico na površini, po čemer so lahko sklepali le, da se je 1,7 metra snega, do koder je bila palica prvotno zabita, medtem že stopilo. Zaradi premalo natančnih meritev z merskim trakom oziroma ocene, kje naj bi bila palica prvotno zabita v sneg, samega premikanja ledenika niso mogli določiti (Meze, 1955).

Ledenik pod Skuto so leta 1997 prvič geodetsko izmerili s tahimetrično metodo izmere. Naslednjo geodetsko meritev so izvedli leta 2003. Od leta 2007 ledenik vsako leto geodetsko izmerijo. Geodetsko izmero izvaja Inštitut za raziskovanje krasa ZRC SAZU.

Pri Ledeniku pod Skuto je bolj kot zmanjševanje površine (preglednica 1) vidno zmanjševanje njegove prostornine. Ob začetku meritev leta 1946 je bila ledeniška površina več deset metrov nad današnjo; to je mogoče oceniti na podlagi starih merilnih točk, s katerimi so označevali rob ledenika. Pred leti so bile te merilne točke na dosegu roke, danes pa so od 40 do 60 metrov višje v ostenju krnice (slika 7). Leta 2006 je bila izmerjena tudi debelina ledenika na dveh podolžnih

2 Predvidene točke za redno fotografiranje: točka blizu totalizatorja na vzhodni strani ledenika, Glava (2426 m), stene pod Triglavskim domom na Kredarici (2516 m), točka na poti s Kredarice proti vrhu Triglava, približno tam, kjer se začne pot strmo dvigati. Zadnji dve stojišči sta bili pozneje izbrani za postavitev železnih palic, ki se še vedno uporabljata kot stalni stojišč fotoaparata Horizont. 
prerezih s parno ledno vrtalno napravo. Povprečna debelina ledenika je bila 7 metrov, njegova največja debelina pa približno 12 metrov. Na podlagi podolžnih prerezov in prečne širine ledenika so leta 2006 njegovo prostornino ocenili na $80.000 \mathrm{~m}^{3}$ (Pavšek, 2007).

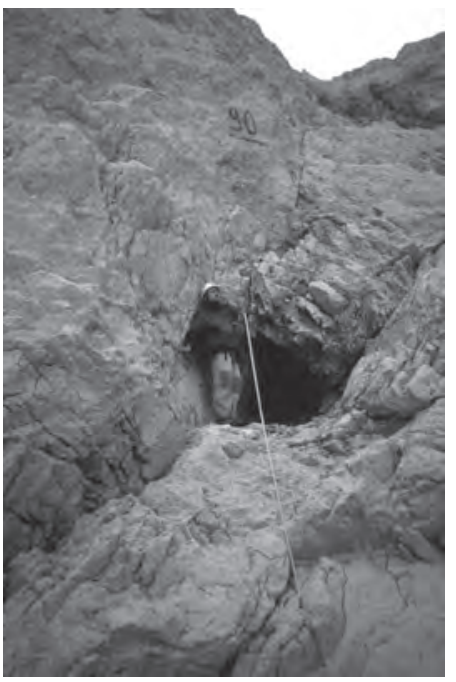

Slika 7: Miha Pavšek meri vertikalno oddaljenost stare merilne točke iz leta 1990 od površja ledenika v letu 1994, ki je pod spodnjim robom fotografije (fotografirala: Katja Kadiš).

Ker planinske poti okrog Ledenika pod Skuto niso tako oblegane kot tiste proti Triglavu, je na voljo manj zgodovinskega fotografskega gradiva s tega območja. Prve (znane) fotografije Ledenika pod Skuto so že omenjene fotografije nesreče iz leta 1913 (slika 2) (Meze, 1955). Vsakoletna fotografiranja ledenika z različnimi nemerskimi fotoaparati z dveh stalnih stojišč so začeli izvajati leta 1962 ob rednih meritvah ledenika konec talilne sezone (Šifrer in Košir,
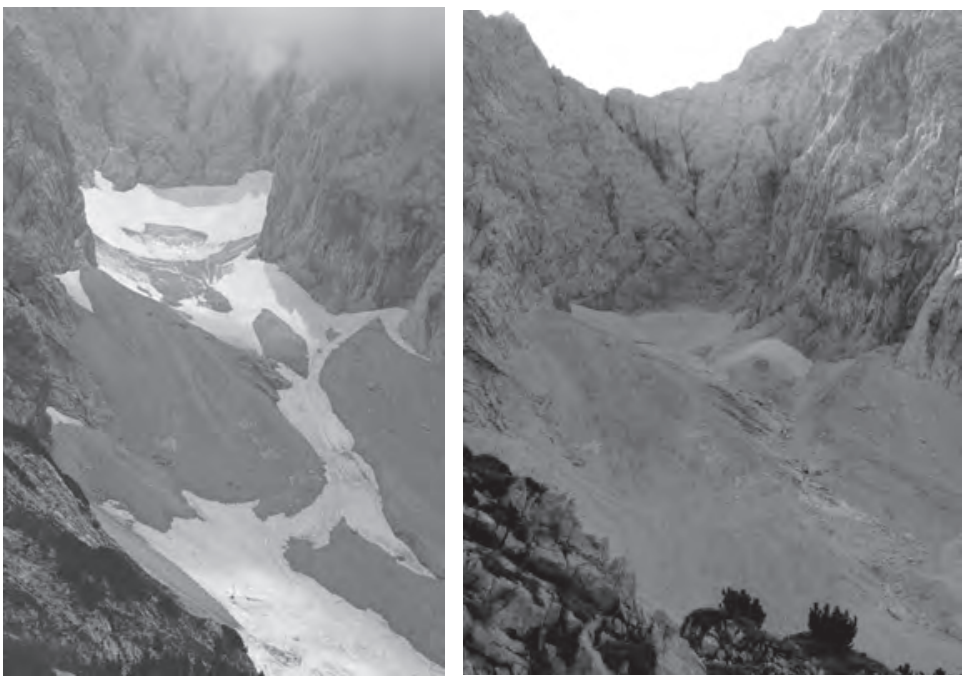

Slika 8: Ledenik pod Skuto, posnet s stalnega stojišča »ob macesnu«, levo leta 1982 (fotograf: Milan Šifrer) in desno leta 2008 (fotograf: Miha Pavšek). 
1976). Približni legi stojišč za fotografiranje: prva je spodnji rob krnice Ledin in druga »ob macesnu« blizu razpotja med Savinjskim sedlom in Rinkami (slika 8). Ta gradiva še čakajo na obdelavo.

\begin{tabular}{|c|c|c|c|c|}
\hline & Površina [l] & & & \\
\hline Leto & $\begin{array}{l}\text { Triglavski } \\
\text { ledenik }\end{array}$ & Vrsta izmere & $\begin{array}{l}\text { Ledenik pod } \\
\text { Skuto }\end{array}$ & Izmera \\
\hline konec 19. stol. & $>40$ & ocena & & \\
\hline 1900 & 30 & ocena & & \\
\hline 1937 & 27 & topografska karta & & \\
\hline 1946 & 14,4 & merski trak & $2,5-3$ & merski trak \\
\hline 1948 & 16,0 & merski trak & & \\
\hline 1950 & 12,7 & merski trak & 2,8 & merski trak \\
\hline 1952 & 12,6 & geodetska izmera & & \\
\hline 1959 & 10,9 & merski trak & & \\
\hline 1964 & 10,3 & merski trak & & \\
\hline 1973 & 11,9 & merski trak & & \\
\hline 1982 & 10,9 & Horizont & & \\
\hline 1989 & 6,8 & Horizont & 1,1 & merski trak \\
\hline 1992 & 4,0 & Horizont & & \\
\hline 1995 & 3,0 & geodetska izmera & & \\
\hline 1997 & 2,9 & Horizont & 1,5 & geodetska izmera \\
\hline 1999 & 1,1 & geodetska izmera & & \\
\hline 2003 & 0,7 & geodetska izmera & 0,7 & geodetska izmera \\
\hline 2007 & 0,6 & geodetska izmera & 1,1 & geodetska izmera \\
\hline
\end{tabular}

Preglednica 1: Zmanjševanje površine Triglavskega ledenika in Ledenika pod Skuto ter metode izmere. Podane so vrednosti za leta, $v$ katerih ledenika nista bila popolnoma prekrita s snegom iz pretekle zime. Po letu 2007 sta bila med meritvami oba redno prekrita s snegom. Vrsta izmere Horizont pomeni, da je površina ocenjena na podlagi arhivskih posnetkov Horizont.

\section{AVSTRIJSKI LEDENIKI}

Približno sto avstrijskih ledenikov vsako leto izmerijo člani Avstrijskega planinskega društva (Österreichischer Alpenverein) s preprostimi metodami. Od točk, zarisanih pred čelom ledenika, z merskim trakom merijo vsakoletni umik ledenikov (Kaufmann in Ladstädter, 2004). Izmere so začeli izvajati že leta 1891 (Finsterwalder et al., 1891); danes za to skrbijo različna društva ali posamezniki, podatke pa zbira Andrea Fischer iz Innsbrucka, ki vsako leto izda povzetek meritev v reviji Bergauf Avstrijskega planinskega društva (na primer Fischer, 2012), podatke pa 
posreduje tudi na World Glacier Monitoring Service v Zürich (http://www.geo.uzh.ch/microsite/ wgms/). Le na nekaterih ledenikih v Avstriji izvajajo tudi tahimetrične meritve sprememb debeline/prostornine ledenika in hitrosti premikanja ledenih gmot ter spremembe v gostoti ledu (preučujejo letno masno bilanco ledenikov). V ta namen spremljajo več ledenikov: Pasterca (Pasterze), Goldbergkees, Kleinfleisskees, Stubacher Sonnblickkees in Wurtenkees v vzhodnem delu avstrijskih Alp ter Jamtalferner, Hintereisferner, Kesselwandferner in Vernagtferner v zahodnem delu. Rezultate objavljajo v letnih poročilih (na primer Zemp et al., 2011). Podatke o letni masni bilanci teh ledenikov prispevajo v Globalno terestrično mrežo ledenikov (Global Terrestrial Network for Glaciers: GTN-G; http://www.gtn-g.org/).

Ker druge meritve večinoma ne omogočajo spremljanja sprememb površine in zmanjševanja debeline ledenikov, so v Avstriji izvedli dve inventarizaciji ledenikov, prvo leta 1969 (Patzelt, 1980) in drugo leta 1998 (Lambrecht in Kuhn, 2007), in sicer s fotogrametričnim stereozajemom in polsamodejno izdelavo DMR-jev. V okviru prve inventarizacije so ugotavljali tudi površine avstrijskih ledenikov v obdobju med letoma 1850 in 1920, ko so bili domnevno največji (Gross, 1987). Nekateri rezultati so podani v preglednici 2.

\begin{tabular}{|l|l|l|l|}
\hline Leto & $\begin{array}{l}\text { Število } \\
\text { ledenikov }\end{array}$ & $\begin{array}{l}\text { Skupna površina } \\
\text { ledenikov }\left(\mathrm{km}^{2}\right)\end{array}$ & $\begin{array}{l}\text { Skupna } \\
\text { prostornina } \\
\text { ledenikov } \\
\left(\mathrm{km}^{3}\right)\end{array}$ \\
\hline 1850 & $/$ & 946 & $/$ \\
\hline 1920 & $/$ & 759 & $/$ \\
\hline 1969 & 925 & 567 & 22,8 \\
\hline 1998 & $\sim 900$ & 471 & 17,7 \\
\hline
\end{tabular}

Preglednica 2: Število ter skupna površina in ocenjena prostornina avstrijskih ledenikov (Gross, 1987; Lambrecht in Kuhn, 2007)

Poleg splošnih meritev, s katerimi spremljajo celotno poledenitev v Avstriji, različne ustanove na posameznih ledenikih izvajajo številne raziskave (tudi geodetske) za podrobnejšo obravnavo sprememb na njih. V nadaljevanju predstavljamo meritve dveh ledenikov, ki ju izvajata Inštitut za geografijo in regionalne študije Univerze v Gradcu ter Inštitut za daljinsko zaznavanje in fotogrametrijo Tehniške univerze v Gradcu.

\subsection{Izmera ledenikov Gössnitzkees in Hornkees}

Sosednja krniška ledenika Gössnitzkees in Hornkees ležita v Schoberjevi gorski skupini (Schobergruppe) v Visokih Turah. Podobno kot slovenska ledenika stojita na relativno nizki nadmorski višini in imata majhno akumulacijsko zaledje. Sta pa veliko obsežnejša od Triglavskega ledenika in Ledenika pod Skuto, saj sta leta 2006 merila še 58,9 in 30,6 hektarjev. Za primerjavo s slovenskima smo ju izbrali še zato, ker je njun obseg podobno vrednoten iz različnih virov vse do leta 1873 , metode izmere pa so dobro dokumentirane. Ker sta ledenika na območju, ki ni 
preveč planinsko oblegano, je tudi tu malo verjetno, da obstajajo stare fotografije. Eno izmed najstarejših vidimo na sliki 9 , na sliki 10 pa je podan primerljiv novejši skupni pogled na ledenika.

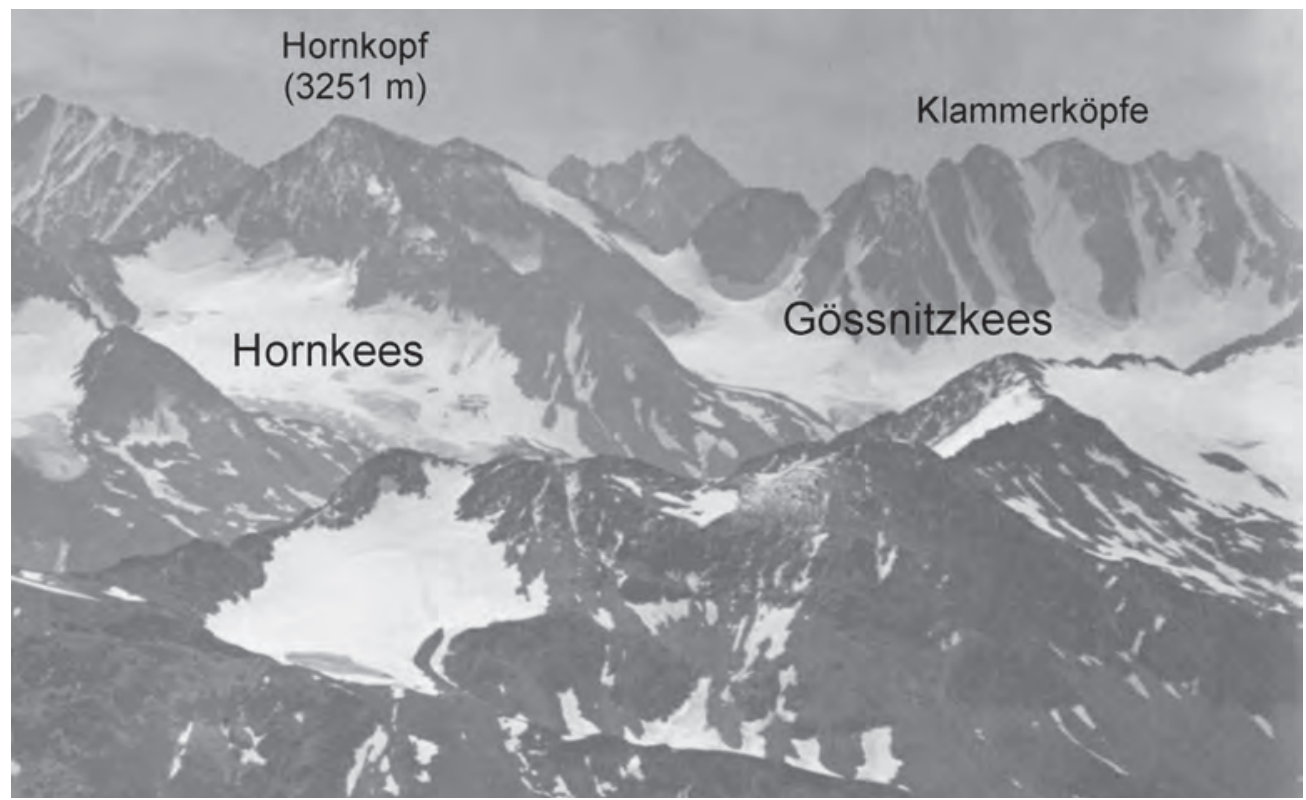

Slika 9: Terestrična fotografija ledenikov Gössnitzkees in Hornkees iz leta 1863, posneta s stojišča v bližini Velikega Kleka (Grossglockner) v smeri proti jugovzhodu (fotograf: Gustav Jägermayer (c)Albertina, Wien (http://www.albertina.at/)).

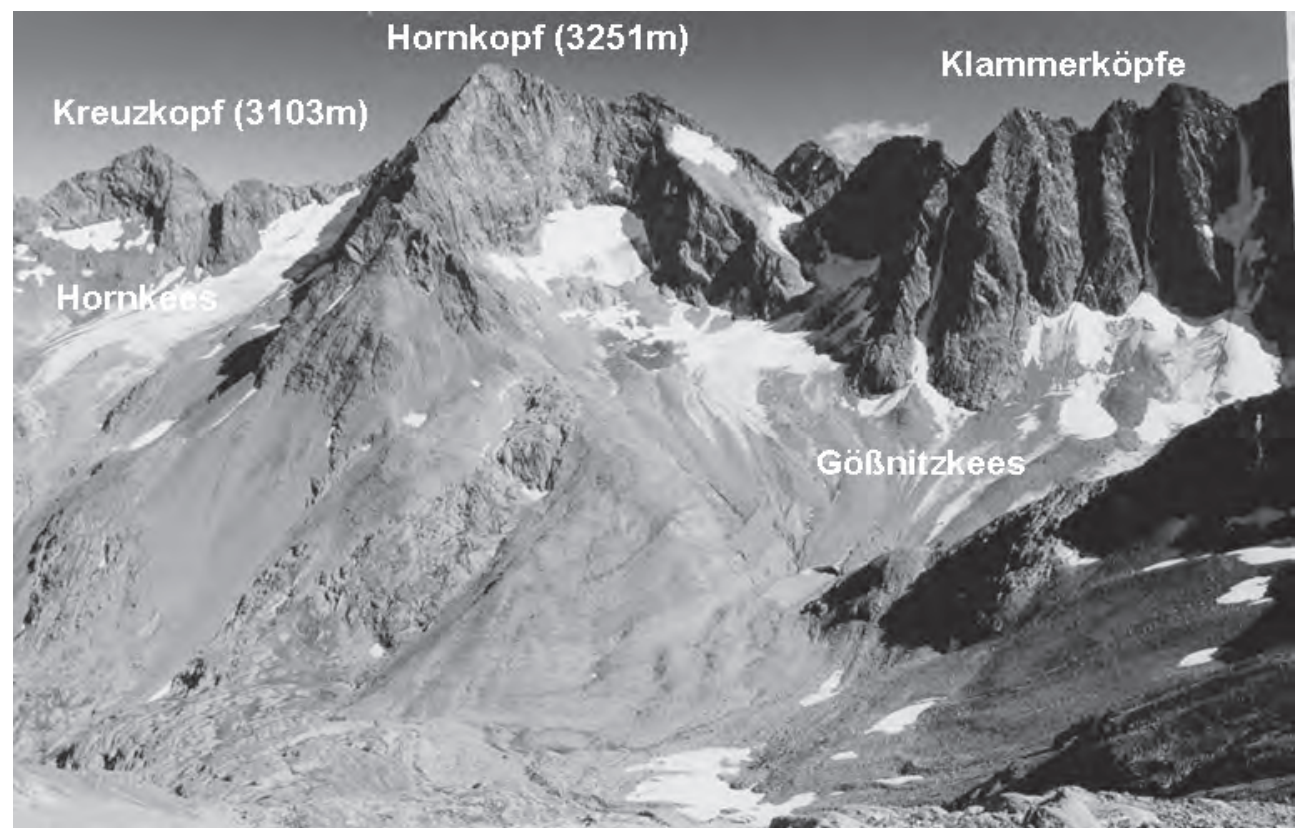

Slika 10: Terestrična fotografija ledenikov Gössnitzkees in Hornkees, posneta poleti 1997 z gore Roter Knopf (fotograf: Gerhard Karl Lieb). 
V Schoberjevi gorski skupini Visokih Tur je prek 30 vrhov višjih od 3000 metrov; najvišji je Petzek (3283 m). Leta 1969 je bilo v tej gorski skupini 29 majhnih ledenikov s povprečno velikostjo $18 \mathrm{ha}^{3}$, največja med njimi sta Gössnitzkees in Hornkees. Skoraj dve tretjini površine ledenika Gössnitzkees sta prekriti z gruščem, sosednji Hornkees je z gruščem manj pokrit, večinoma le na robovih. Njegova višinska razporeditev je ugodnejša za daljši obstoj ledenika, saj večina leži nekoliko višje od sosednjega Gössnitzkeesa. Najnižji del ledenika Gössnitzkees je bil leta 1850 na višini 2465 metrov, leta 1997 pa na 2515 metrih; najvišji del ledenika je na višini 3000 metrov. Najnižji del ledenika Hornkees je bil leta 1850 na 2406 metrih, leta 1996 pa na 2600 metrih. Ledenik Gössnitzkees ima tudi ledeniško jezero, ki ga napaja v poletnih mesecih. Leta 2006 je Gössnitzkeesjevo ledeniško jezero merilo 0,7 hektarja (Kaufmann in Lieb, 2002; Kaufmann in Ladstädter, 2008a).

Obseg ledenikov Gössnitzkees in Hornkees za leti 1873 in 1929 so vektorizirali iz starih topografskih zemljevidov. Obseg iz leta 1873 je sicer vprašljiv, saj so bili ledeniki na tem zemljevidu slabše predstavljeni. Prvi topografski zemljevid, na katerem so bile ledeniške izohipse dobro predstavljene, je iz leta 1929 (Kaufmann in Ladstädter, 2008a).

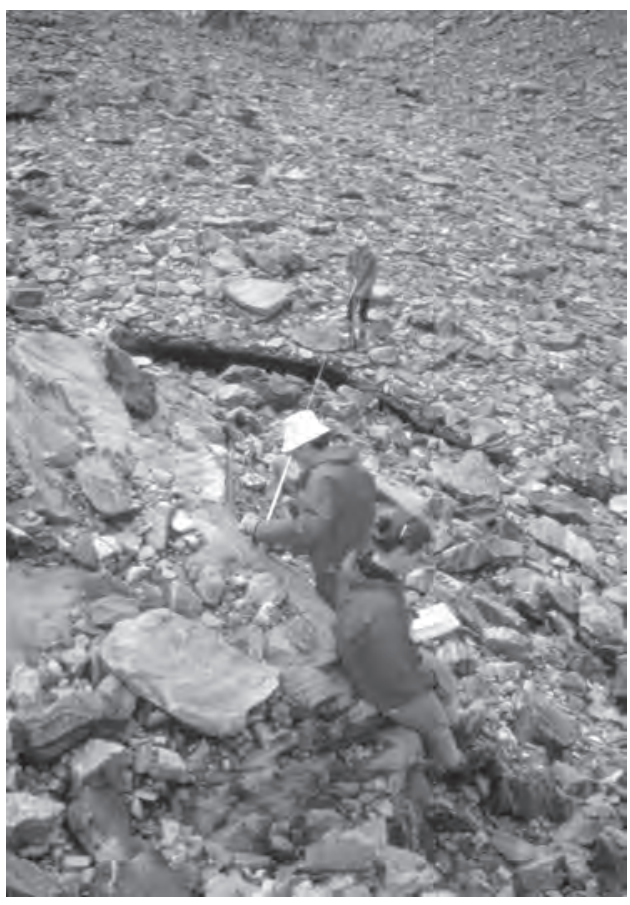

Slika 11: Prva ponovitev meritev umikanja ledenika Gössnitzkees z merskim trakom v letu 1983 od merilne točke, stabilizirane $v$ letu 1982. Viktor Kaufmann stoji na robu ledenika, ki je gosto prekrit z gruščem, Gerhard Karl Lieb odčitava razdalje na merskem traku, Bettina Hofer piše zapisnik meritev (fotografinja: Elmar Joura).

Prve meritve ledenika Gössnitzkees sta izvedla Lieb in Kaufmann leta 1982. Najprej sta z merskim trakom merila umikanje čela ledenika od dveh stalnih merilnih točk, ki sta ju označila

\footnotetext{
${ }^{3}$ Takrat je tudi Triglavski ledenik meril približno 15 hektarjev.
} 
z obstojno barvo na trdni skali leta 1982 (slika 11). Koordinate točk sta izračunala v lokalnem koordinatnem sistemu s trilateracijo. Leto kasneje sta izmerila še sosednji Hornkees. Od takrat vsako leto merijo oba ledenika sodelavci Inštituta za geografijo in regionalne študije Univerze v Gradcu ter Inštituta za daljinsko zaznavanje in fotogrametrijo Tehniške univerze v Gradcu. Leta 1996 si je takratni Inštitut za geodezijo Univerze v Grazu izbral Gössnitzkees kot testno območje za svoje alpske študije (Kaufmann, 2012).
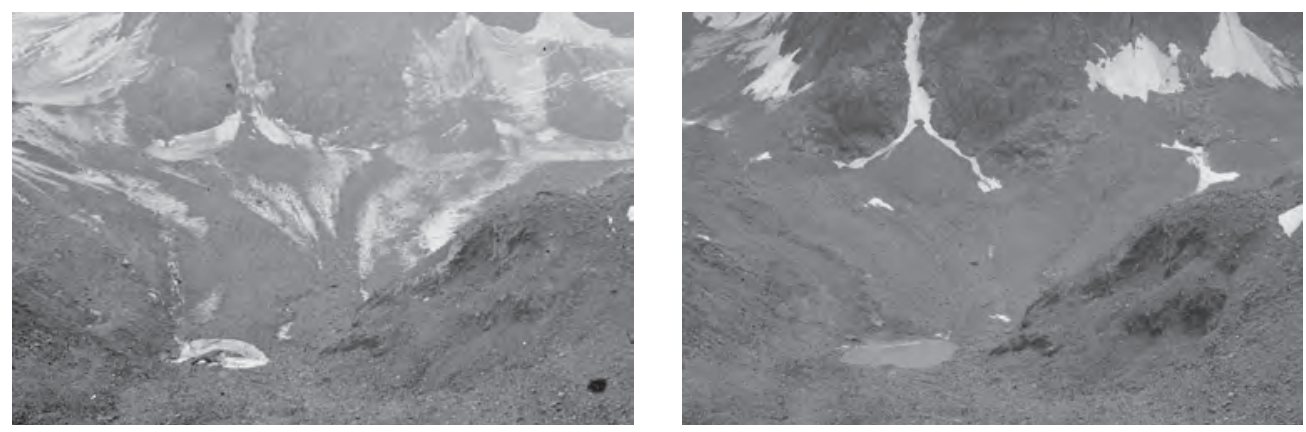

Slika 12: Pogled na osrednji del ledenika Gössnitzkees. Levo je posnetek z dne 7. septembra 1988, posnet s fototeodolitom Zeiss TAL (fotografa: Robert Kostka in Viktor Kaufmann). Desno pa je posnetek z dne 20. avgusta 2010, posnet z digitalnim fotoaparatom Nikon D300. Na desni fotografiji je vidno tudi ledeniško jezero. Posnetka sta narejena z istega stojišča (fotograf: Viktor Kaufmann).

Pred letom 1954 ne obstajajo terestrične ali aerofotografije ledenikov, zato so obseg ledenika za leto 1850 določili na podlagi terenskega preučevanja čelnih in stranskih moren. Največji doseg ledenikov lahko na podlagi ledeniških moren vidimo tudi na novejših aeroposnetkih. Stanje ledenikov v letih 1954, 1969, 1974, 1983, 1992, 1997, 2002 in 2006 je izmerjeno na podlagi aerofotogrametričnih snemanj (posnetke hranijo v avstrijskem arhivu aeroposnetkov - Bundesamt für Eich-und Vermessungswesen). Dodatna aerofotogrametrična snemanja so bila izvedena v letih 1997 in 1998. Večina posnetkov je bila narejena septembra, ko se navadno konča talilno obdobje ledenikov. Izjeme so le naslednja leta: 1969 (posneto v oktobru), 1983 (posneto v juliju) in 1998 (posneto konec avgusta). Fotogrametrično izvrednotenje vseh aeroposnetkov iz različnih virov je bilo izvedeno v skupnem koordinatnem sistemu avstrijske Gauss-Krügerjeve kartografske projekcije v merilu $1: 5000$. Izvrednotili so izohipse, lomne linije, grebene, razvodnice, višinske točke, obode snežišč in ledenikov ter druge topografske vsebine. Ledenika je bilo ponekod težko omejiti, saj sta deloma pokrita z gruščem. Stereozajem je bil otežen tudi na delih, kjer sta bila močno obsijana s soncem ali pa sta bila v močni senci (Kaufmann in Ladstädter, 2002; Kaufmann in Ladstädter, 2008a).

Na delu ledenika Gössnitzkees od leta 1988 izvajajo tudi terestrična fotogrametrična snemanja. Na najdaljšem in najdebelejšem prerezu osrednjega dela ledenika s fotogrametrijo merijo njegovo tanjšanje. Terestrična fotogrametrična snemanja so izvedli v letih 1988, 1997, 2003, 2004, 2005, 2006 in 2007. V prvem letu so izvedli normalno snemanje z dveh stabiliziranih stojišč, ki so jima v naslednjih letih dodali še dve dodatni stabilizirani stojišči. Stojišča so stabilizirana z vijaki in izbrana tako, da testni prerez ledenika vidimo samo na enem stereoparu (slika 12). V vseh letih so uporabili različne merske in nemerske (naknadno kalibrirane) fotoaparate. Leta 1988 
so uporabili fototeodolit Zeiss TAL na steklene plošče dimenzije $6 \mathrm{~cm} \times 6 \mathrm{~cm}$, v letih 1997 in 2003 merski fotoaparat srednjega formata Rollemetric 6006, v letih 2004, 2005 in 2006 nemerski digitalni fotoaparat malega formata Nikon D100, leta 2006 so uporabili še nemerski digitalni fotoaparat višje kakovosti Hasselblad H2D-39, leta 2007 pa nemerski digitalni fotoaparat Nikon D80. Nemerske fotoaparate so pri uporabi in kalibraciji nastavili na neskončnost. Kalibrirali so jih s kalibracijsko tarčo, priloženo programu Photomodeler. Prvih sedem naravnih značilnosti, ki so jih vzeli za oslonilne točke, so izmerili v lokalnem koordinatnem sistemu s fototeodolitom že leta 1988. Naknadno so ugotovili, da te točke niso dovolj natančno določene za želeno natančnost fotogrametričnega izvrednotenja, zato so leta 2003 tahimetrično izmerili še deset novih naravnih značilnosti, ki so jih privzeli za oslonilne točke za absolutno orientacijo v državnem koordinatnem sistemu. Naravne značilnosti v prostoru so izbrali tako, da geodetska izmera novih oslonilnih točk na terenu ni več potrebna. Na podlagi absolutno orientiranega stereopara iz leta 2003 so izmerili dodatnih 55 fotogrametričnih oslonilnih točk. Tako je za absolutno orientacijo stereoparov iz drugih let na voljo skupno 65 oslonilnih točk (Kaufmann in Ladstädter, 2004; Kaufmann in Ladstädter, 2008b).

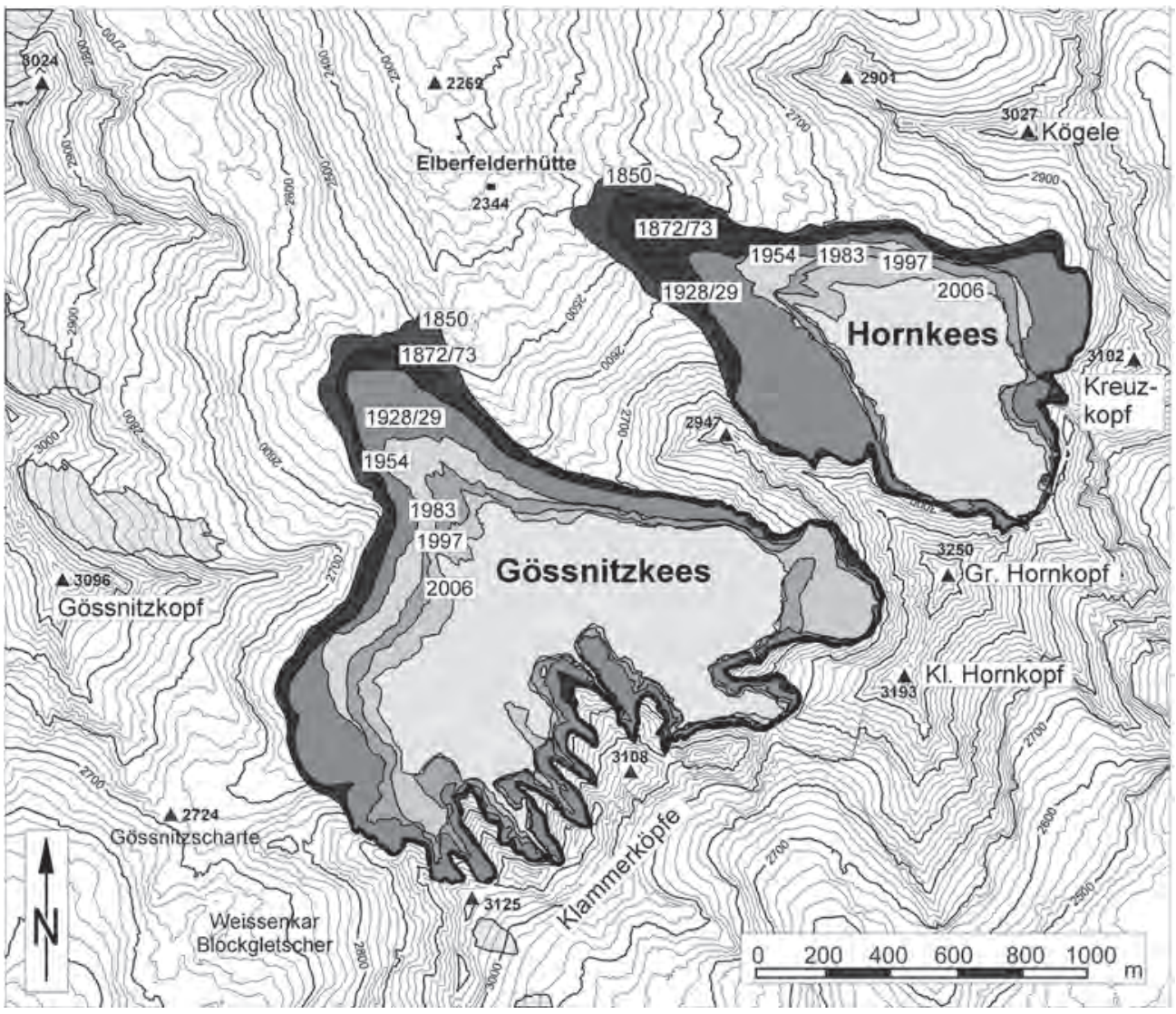

Slika 13: Zmanjševanje površine ledenikov Gössnitzkees in Hornkees (preglednica 3) 


\begin{tabular}{|l||c|c|l|}
\cline { 2 - 4 } \multicolumn{1}{c|}{} & \multicolumn{2}{l|}{ Površina [ha] } \\
\hline Leto & $\begin{array}{l}\text { Ledenik } \\
\text { Gössnitzkees }\end{array}$ & $\begin{array}{l}\text { Ledenik } \\
\text { Hornkees }\end{array}$ & Izmera \\
\hline \hline 1873 & 146,1 & 84,4 & topografska karta \\
\hline 1929 & 132,3 & 70,5 & topografska karta \\
\hline 1954 & 97,3 & 43,9 & aerofoto stereozajem \\
\hline 1969 & 93,3 & 42,2 & aerofoto stereozajem \\
\hline 1974 & 89,9 & 41,7 & aerofoto stereozajem \\
\hline 1983 & 90,1 & 41,3 & aerofoto stereozajem \\
\hline 1992 & 78,3 & & aerofoto stereozajem \\
\hline 1997 & 75,7 & 36,1 & aerofoto stereozajem \\
\hline 2002 & 63,3 & 33,0 & aerofoto stereozajem \\
\hline 2006 & 58,8 & 30,6 & aerofoto stereozajem \\
\hline
\end{tabular}

Preglednica 3: Zmanjševanje površine ledenikov Gössnitzkees in Hornkees ter metode izmere

Spodnji del ledenika Gössnitzkees od leta 1996 vsako leto tudi tahimetrično merijo, in sicer umikanje čela ledenika, obod ledeniškega jezera, premikanje ledenika z desetih stalnih stabiliziranih točk, izmerijo pa tudi dva prereza ledenika do višine 2570 metrov. Nad to višino je ledenik prestrm za vsakoletno postavljanje reflektorjev za merjenje dolžin. Na podlagi meritev so določili hitrost premikanja ledenika na med 0,2 in 0,5 metra na leto (Kienast in Kaufmann, 2004; Kaufmann in Ladstädter, 2004).

Površine ledenikov med letoma 1873 in 2006 so predstavljene na sliki 13, v preglednici 3 je navedena še metoda izmere.

\section{SKLEP}

$\mathrm{Na}$ predstavljenih ledenikih se uporabljajo primerljive tehnike merjenja, toda neposredna primerjava zmanjševanja površine zaradi razlike $\mathrm{v}$ velikosti med avstrijskima in slovenskima ledenikoma ni najbolj primerna, čeprav so vidni nekateri trendi (preglednica 4). Kot smo prikazali v preglednicah 1 in 2, sta ledenika Gössnitzkees in Hornkees leta 2006, ko sta bila najmanjša, merila 58,9 in 30,6 hektarjev. Triglavski ledenik je imel najmanjšo izmerjeno površino leta 2007, in sicer 0,6 hektarja, Ledenik pod Skuto pa leta 2003, in sicer 0,7 hektarja.

V preglednici 3 primerjamo zmanjševanje Triglavskega ledenika ter ledenikov Gössnitzkees in Hornkees. Vidimo, da so se pospešeno zmanjševali od 30ih let prejšnjega stoletja vse do 50ih let prejšnjega stoletja, ko so izgubili povprečno hektar površine na leto. Od srede stoletja pa vse do začetka 80 ih let prejšnjega stoletja so vsi trije ledeniki stagnirali in so večinoma izgubljali po približno 0,1 hektarja na leto. Po letu 1983 se je pri vseh začelo pospešeno upadanje površine. Zadnji dve obdobji zaradi majhne površine Triglavskega ledenika (približno en hektar) nista neposredno primerljivi. 


\begin{tabular}{|l||l|l||l|l|}
\cline { 2 - 5 } \multicolumn{1}{c|}{} & \multicolumn{3}{l|}{ Letno kolebanje ledenikov [ha/leto] } \\
\hline Obdobje & $\begin{array}{l}\text { Ledenik } \\
\text { Gössnitzkees }\end{array}$ & Ledenik Hornkees & Obdobje & $\begin{array}{l}\text { Triglavski } \\
\text { ledenik }\end{array}$ \\
\hline \hline $1873 / 1929$ & $-0,25$ & $-0,25$ & & \\
\hline $1929 / 1954$ & $-1,40$ & $-1,06$ & $1937 / 1954$ & $-0,80$ \\
\hline $1954 / 1969$ & $-0,27$ & $-0,11$ & $1954 / 1967$ & $-0,10$ \\
\hline $1969 / 1974$ & $-0,67$ & $-0,10$ & $1967 / 1973$ & 0 \\
\hline $1974 / 1983$ & $+0,03$ & $-0,05$ & $1973 / 1983$ & $-0,18$ \\
\hline $1983 / 1992$ & $-1,32$ & $-0,37(1983 / 1997)$ & $1983 / 1992$ & $-0,64$ \\
\hline $1992 / 1997$ & $-0,52$ & & $1992 / 1997$ & $-0,28$ \\
\hline $1997 / 2002$ & $-2,46$ & $-0,62$ & $1997 / 2003$ & $-0,37$ \\
\hline $2002 / 2006$ & $-1,12$ & $-0,60$ & $2003 / 2007$ & $-0,03$ \\
\hline
\end{tabular}

Preglednica 4: Letno kolebanje površine ledenikov Gössnitzkees in Hornkees ter Triglavskega ledenika. Letna vrednost je izračunana z deljenjem razlike površin s številom let $v$ določenem obdobju.

Alpskim ledenikom je skupno, da so imeli največje obsege v zadnjih stoletjih na sredini 19. stoletja (Zängl in Hamberger, 2004), ob enem od vrhuncev tako imenovane male ledene dobe (Fagan, 2000). Leta 1870 so alpski ledeniki pokrivali okrog $4400 \mathrm{~km}^{2}$ (dobra $2 \%$ površine Alp), njihova prostornina pa je bila približno $200 \mathrm{~km}^{3}$. Do sedemdesetih let 20. stoletja se je njihova skupna prostornina zmanjšala na $140 \mathrm{~km}^{3}$, do začetka 21. stoletja pa so izgubili še dodatno tretjino prostornine (približno $90 \mathrm{~km}^{3}$ ). Prostornina alpskih ledenikov se je tako v dobrem stoletju in pol zmanjšala za dobro polovico, površina pa za približno tretjino (Haeberli et al., 2007; Haeberli in Beniston, 1998; Funk-Salamí, 2004; Zängl in Hamberger, 2004; Barry, 2006). Te spremembe so povezane z različnimi podnebnimi spremembami (Kerschner, 2002). Za območje Triglavskega ledenika ugotavljajo, da je v primerjavi s preteklimi obdobji zdaj tam tanjša spomladanska snežna odeja,višje so poletne temperature, več pa je tudi sončnega obsevanja v talilni sezoni (Dolinar, 2010). Med podnebnimi spremembami se največkrat izpostavljajo višje povprečne letne temperature. Te se od sredine 19 . stoletja dvigujejo za približno $0,7-1^{\circ} \mathrm{C}$ na sto let; pri Triglavskem ledeniku je bila povprečna poletna temperatura sredi 19 . stoletja pod $5^{\circ} \mathrm{C}$, leta 2010 pa okrog $6,5^{\circ} \mathrm{C}$. Po napovedih se bo trend dvigovanja temperatur še nadaljeval, saj naj bi se povprečne letne temperature v Alpah do konca 21 . stoletja dvignile za $1,4-5,6^{\circ} \mathrm{C}$ (Maisch, 2004). Na podlagi teh scenarijev se alpskim ledenikov obeta podobna usoda kot pred malo ledeno dobo. Kratkoročno so najbolj ogroženi prav majhni alpski ledeniki, predvsem tisti na relativno nizkih nadmorskih višinah (na primer slovenska ledenika). Enako velja za ledenike na podobnih višinah, a v nižjih geografskih širinah, na primer v Albaniji (Hughes, 2010), Črni gori (Djurović, 2012) ali Bolgariji (Grunewald in Scheithauer, 2010), če se omejimo le na Balkan. $\mathrm{Na}$ primeru dveh slovenskih in dveh avstrijskih ledenikov vidimo, da se poleg geodetskih in 
fotogrametričnih metod izmere za preučevanje ledenikov velikokrat še vedno uporabljajo tudi približne meritve z merskim trakom. Skupek različnih meritev lahko v različnih časovnih presekih poda podroben dolgoročni trend zmanjševanja ledenikov. Danes se za njihovo spremljanje vse bolj uporablja tudi zračno lasersko skeniranje, s katerim dobimo še natančnejšo predstavitev same površine ledenika (na primer Abermann et al., 2009). V letu 2012 bo takšna izmera opravljena tudi na slovenskih ledenikih.

\section{ZAHVALA}

Delo je bilo delno financirano v okviru projektov L6-7136 (C) in Z2-4182 (B) Javne agencije za raziskovalno dejavnost Republike Slovenije (ARRS) in FWF P18304-N10 Avstrijskega raziskovalnega sklada (Fonds zur Förderung der wissenschaftlichen Forschung - FWF).

\section{Literatura in viri:}

Abermann, J., Lambrecht, A., Fischer, A., Kuhn, M. (2009). Quantifying changes and trend in glacier area and volume in the Austrian Otztal Alps (1969-1997-2006), The Cryosphere, 3, 205-215.

Avian, M., Bauer, A. (2006). First results on monitoring glacier dynamics with the aid of the terrestrial laser scanning on Pasterze glacier (Hohe Tauern, Austria). Glazier Schriften der Geographie und Raumforschung, 41, 27-36.

Barry, R. G. (2006). The status of research on glaciers and global glacier recession: a review. Progress in Physical Geography, 30(3), 285-306.

Bayr, K. J., Hall, D. K., Kovalick, W. M. (1994). Observations on glaciers in the eastern Austrian Alps using satellite data. International Journal of Remote Sensing, 15, 1733-1742.

Bolch, T., Kamp, U. (2006). Glacier mapping in high mountains using DEMs, Landsat and ASTER data. Glazier Schriften der Geographie und Raumforschung, 41, 37-48.

Djurović, P. (2012). The Debeli Namet glacier (Durmitor, Montenegro) - From the second half of the 20th century to the present. Acta geographica Slovenica, 52 (v tisku).

Dolinar, M. (ur.) (2010). Spremenljivost podnebja v Sloveniji. Ljubljana: Agencija Republike Slovenije za okolje. http:// meteo.arso.gov.si/uploads/probase/www/climate/text/sl/publications/spremenljivost\%20podnebja.pdf. (2. 4. 2012).

Fagan, B. (2000). The Little Ice Age: How Climate Made History, 1300-1850. New York: Basic Books.

Finsterwalder, S., Hann, J., Partsch, J., Penck, A., Richter, E. (1891). Aufruf. Mitteilungen des Deutschen und Österreichischen Alpenvereins, 17(8), 106-107.

Fischer, A. (2012). Gletscherbericht 2010/2011. Bergauf 67(2), 30-36.

Funk-Salami, F. (2004). Naturwunder aus Eis. In Gletscher im Treibhaus. Steinfurt: Tecklenborg Verlag, 194-199.

Gabrovec, M. (2002). Triglavski ledenik = The Triglav glacier. In Visokogorska jezera v vzhodnem delu Julijskih Alp= High-Mountain Lakes in the Eastern Part of the Julian Alps. Ljubljana: Založba ZRC, 37-48.

Gabrovec, M. (2008). II ghiacciaio del Triglav (Slovenia) = The Triglav glacier. Ghiacciai montani e cambiamenti climatici nell' ultimo secolo. Terra glacialis - Edizione speciale, 75-87.

Gross G. (1987). Der Flächenverlust der Gletscher in Österreich 1850-1920-1969. Zeitschrift für Gletscherkunde und Glazialgeologie, 23(2), 131-141.

Grunewald, K., Scheithauer, J. (2010). Europe's southernmost glaciers: response and adaptation to climate change. Journal of Glaciology, 56(195), 129-141.

Haeberli, W., Beniston, M. (1998). Climate change and its impacts on glaciers and permafrost in the Alps. Ambio, 27(4), 258-265.

Haeberli, W., Hoelzle, M., Paul, F., Zemp, M. (2007). Integrated monitoring of mountain glaciers as key indicators of global climate change: the European Alps. Annals of Glaciology, 46(1), 150-160.

Hagg, W., Mayer, C., Steglich, C. (2008). Glacier changes in the Bavarian Alps from 1989/90 to 2006/2007. Zeitschrift 
für Gletscherkunde und Glazialgeologie, 42(1), 37-46.

Hughes, P. D. (2010). Little Ice Age glaciers in the Balkans: low altitude glaciation enabled by cooler temperatures and local topoclimatic controls. Earth Surface Processes and Landforms, 35, 229-241.

Kaufmann, V., Lieb, G. K. (2002). Investigation on the retreat of two small cirque glaciers (Goessnitzkees and Hornkees) in the Austrian Alps, Europe. Hight-Mountain Remote Sensing Cartography 1998: 5th International Symposium on the Use of Remote Sensing Data in Mountain Cartography, Karlstad University Studies, 27, 75-82.

Kaufmann, V., Ladstädter, $R$. (2004). Documentation of the retreat of small debries-covered cirque glacier (Gössnitzkees, Austrian Alps) by means of terrestrial photorammetry. 4th ICA Mountain Cartography Workshop, 65-76.

Kaufmann, V., Ladstädter, R. (2008a). Documentation of the retreat of Gössnitzkees and Hornkees glaciers (Hohe Tauern Range, Austria) for the time period 1997-2006 by means of aerial photogrammetry. 6th ICA Mountain Mapping and Visualisation, 131-139.

Kaufmann, V., Ladstädter, R. (2008b). Application of terrestrial photogrammetry for glacier monitoring in Alpine environments. The International Archives of the Photogrammetry, Remote Sensing and Spatial Information Sciences, 37, part B8, 813-818.

Kaufmann, V. (2012). Goessnitzkees (Carinthia, Austria), www.geoimaging.tugraz.at/viktor.kaufmann/Goessnitzkees. html (2. 4. 2012).

Kerschner, H. (2002). Gletscher-Klima-Beziehungen als klimageschichtliche Werkzeuge. Grazer Schriften der Geographie und Raumordnung, 38, 143-158.

Kienast, G., Kaufman, V. (2004). Geodetic measurements on glaciers and rock glaciers in the Hohe Tauern National Park (Austria). 4th ICA Mountain Cartography Workshop. www.geoimaging.tugraz.at/viktor.kaufmann/HMC2004_ Kienast.pdf. (2. 4. 2012).

Knoll, C., Kerschner, H. (2009). A glacier inventory for South Tyrol, Italy, based on airborne laser-scanner data. Annals of Glaciology, 50(53), 46-52.

Kunaver, J. (1913). Nesreča na Skuti. Planinski vestnik, 19(8), 170-175.

Kunaver, P. (1949). Izpremembe okoli Triglava. Planinski vestnik, 49, 65-75.

Kuhn, M. (1979). Climate and Glaciers, Sea Level, Ice, and Climatic Change (Proceedings of the Canberra Ayplosium, December 1979). IAHS Publication, 131, 3-20.

Lambrecht, A., Kuhn, M. (2007). Glacier changes in the Austrian Alps during the last three decades, derived from the new Austrian glacier inventory. Annals of Glaciology, 46, 177-184.

Lieb, G. K. (2004). Die Pasterze als Beispiel eines schwindenden Gletschers. In Gletscher im Treibhaus. Steinfurt: Tecklenborg Verlag, 216-219.

Maisch, M. (2004). Gletscher im Brennpunkt des Klimawandels. In Gletscher im Treibhaus. Steinfurt: Tecklenborg Verlag, 204-214.

Pavšek, M. (2007). Ledenik pod Skuto kot pokazatelj podnebnih sprememb v slovenskem delu Alp. Dela, 28, 207-219.

Patzelt G. (1980). The Austrian glacier inventory: status and first results. Proceedings of the Riederalp Workshop. IAHS Publication, 126, 181-183.

Meze, D. (1955). Ledenik na Triglavu in Skuti. Geografski zbornik, 3, 10-114.

Natek, M., Perko, D. (1999). 50 let Geografskega inštituta Antona Melika ZRC SAZU. Geografija Slovenije, 1. Ljubljana: Založba ZRC.

Šifrer, M. (1963). Nova geomorfološka dognanja na Triglavu. Triglavski ledenik v letih 1954-1962. Geografski zbornik, $8,157-210$.

Šifrer, M., Košir, D. (1976). Nova dognanja na Triglavskem ledeniku in ledeniku pod Skuto. Geografski zbornik, 15, 213-269.

Triglav, M., Kosmatin Fras, M., Gvozdanovič, T. (2000). Monitoring of glacier surfaces with photogrammetry, a case study of the Triglav Glacier. Geografski zbornik, 40, 7-30.

Triglav Čekada, M., Gabrovec, M. (2008). Zgodovina geodetskih meritev na Triglavskem ledeniku. Geodetski vestnik, 52(3), 508-519. 
Triglav Čekada, M., Radovan, D., Gabrovec, M., Kosmatin Fras, M. (2011). Acquisition of the 3D boundary of the Triglav glacier from archived non-metric panoramic images. The Photogrammetrical Record, 26(133), 111-129.

Triglav Čekada, M. (2012). Geodetske in fotogrametrične meritve Triglavskega ledenika. Raziskave s področja geodezije in geofizike 2011: zbornik predavanj, 7-17.

Triglav Čekada, M., Gabrovec, M. (2012). Documentation of Triglav glacier using non-metric panoramic images, Annals of Glaciology, IGS: Seasonal snow and ice conference (v tisku).

Verbič, T., Gabrovec, M. (2002). Georadarske meritve na Triglavskem ledeniku. Geografski vestnik, 74(1), 25-42.

Zängl, W., Hamberger, S. (2004). Gletscher im Treibhaus. Steinfurt: Tecklenborg Verlag.

Zemp, M., Nussbaumer, S. U., Gaertner-Roer, I., Hoelzle, M., Paul, F., Haeberli, W. (ur.) (2011). Glacier mass balance bulletin. Bulletin, 11 (2008-2009). Zürich: World Glacier Monitoring Service. www.wgms.ch/mbb/mbb11/ wgms_2011_gmbb11.pdf (2. 4. 2012).

Prispelo v objavo: 22. junij 2012

Sprejeto: 2 september 2012

dr. Mihaela Triglav Čekada, univ. dipl. inž. geod.

Geodetski inštitut Slovenije

Jamova 2, SI-1000 Ljubljana

e-pošta:mihaela.triglav@gis.si

doc. dr. Matija Zorn, univ. dipl. geog. in prof. zgod.

Geografski inštitut Antona Melika, Znanstvenoraziskovalni center Slovenske akademije znanosti in umetnosti

Gosposka ulica 13, SI-1000 Ljubljana

e-pošta:matija.zorn@zrc-sazu.si

izr. prof. dr. Viktor Kaufmann

Institut für Fernerkundung und Photogrammetrie, Technische Universität Graz

Steyrergasse 30, A-8010 Graz, Austria

e-pošta: viktor.kaufmann@tugraz.at

izr. prof. dr. Gerhard Karl Lieb

Institut für Geographie und Raumforschung, Karl-Franzens-Universität Graz

Heinrichstraße 36, A-8010 Graz, Austria

e-pošta: gerhard.lieb@uni-graz.at 